\title{
Photoluminescence studies in swift heavy ion bombarded mullite
}

\author{
H. Nagabhushana ${ }^{\text {a }}$, B.N. Lakshminarasappa ${ }^{\mathrm{a}, *}$, Fouran Singh ${ }^{\mathrm{b}}$, D.K. Avasthi ${ }^{\mathrm{b}}$ \\ a Department of Physics, Bangalore University, Jnana Bharathi Campus, Bangalore 560 056, India \\ ${ }^{\mathrm{b}}$ Nuclear Science Centre, Aruna Asaf Ali Marg, New Delhi 110 067, India
}

Received 14 May 2003

\begin{abstract}
Photoluminescence (PL) of pelletized mullite samples irradiated with $100 \mathrm{MeV}$ swift $\mathrm{Ni}^{8+}$ ions with fluences in the range $1 \times 10^{11}-5 \times 10^{13}$ ions $/ \mathrm{cm}^{2}$ have been studied at RT. A broad and strong PL emission band with peak at $\sim 537 \mathrm{~nm}$ besides a sharp emission band with peak at $\sim 705 \mathrm{~nm}$ have been recorded in combustion synthesized mullite. However, a single broad emission with peak at $\sim 537 \mathrm{~nm}$ have been recorded in mullite synthesized by sol-gel technique at an excitation of $442 \mathrm{~nm}$ laser beam. It is found that PL intensity is decreases with increase of $\mathrm{Ni}^{8+}$ ion fluence. The decrease in PL intensity is attributed to destruction of $\mathrm{Al}-\mathrm{O}$ and $\mathrm{Si}-\mathrm{O}$ bonds in the samples. Infrared absorption (IR) studies of as it is and $\mathrm{Ni}^{8+}$ ion irradiated mullites have also been studied and results obtained are discussed.

(c) 2003 Elsevier B.V. All rights reserved.
\end{abstract}

Keywords: Photoluminescence; Infrared spectroscopy; Sol-gel technique; Combustion synthesis; Amorphization; Ion beam

\section{Introduction}

Good amount of work, though not exhaustive, with heavy ion beams on alkali halides and other materials has been reported [1-5]. The energy loss mechanisms for low energy heavy ions have been well studied [6]. High-energy ions upon entering a medium loses its energy initially through the process of electronic excitation and ionization known as electronic energy loss, and at the end of its

\footnotetext{
* Corresponding author. Tel.: +91-80-6748145; fax: +91-803219295.

E-mail address: bnlnarasappa@rediffmail.com (B.N. Lakshminarasappa).
}

range, loses its energy mostly through the process of nuclear loss, in which the lattice atoms of the medium are displaced due to nuclear elastic collisions. The later phenomenon of energy loss becomes prominent when the ion energy reduces to $\sim X \mathrm{keV}$, where $X$ is the atomic weight of the ion. In the surface region of the sample through which an ion enters, the energy loss suffered by a heavy ion through electronic excitation is greater by three orders of magnitude than that through nuclear elastic collisions. In this way the energy deposited in the surface region through elastic collisions should have negligible contribution in defect formation. As such in the sample exposed to high-energy heavy ions, the atoms in the surface 


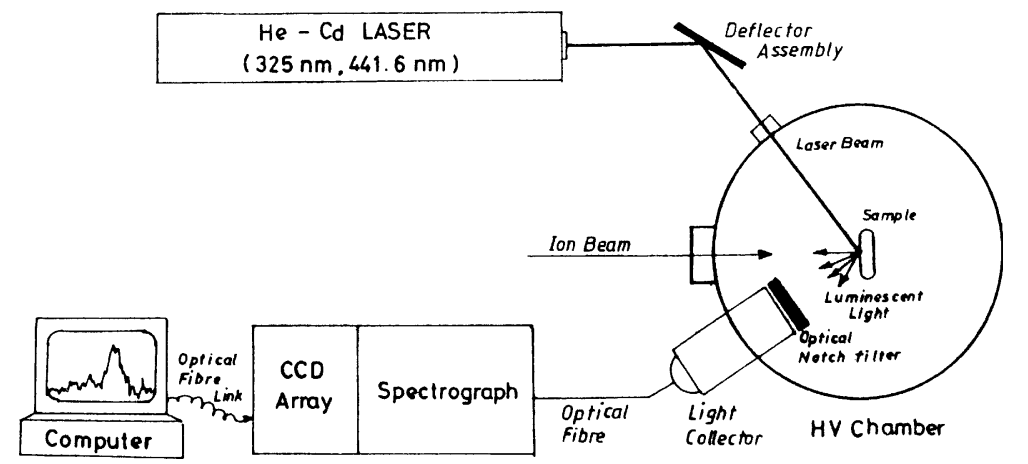

Fig. 1. Experimental setup used for in situ photoluminescence measurements.

region are not expected to get displaced from their lattice positions. The other processes through which defects may be induced to heavy ions are due to Coulomb explosion [7] and thermal spike [8].

In this paper we report the PL and IR results of mullite irradiated with $100 \mathrm{MeV} \mathrm{Ni}{ }^{8+}$ ion for fluences in the range $1 \times 10^{11}-5 \times 10^{13}$ ions $/ \mathrm{cm}^{2}$. Mullite is an aluminum silicate $\left(3 \mathrm{Al}_{2} \mathrm{O}_{3} \cdot 2 \mathrm{SiO}_{2}\right)$ crystallizes in orthorhombic. This is a promising material for high temperature applications because of its low thermal conductivity. The silicate group of this mineral used in the production of nonfusion cast tank blocks, in the manufacture of spark plugs and as a mineral specimens [9].

\section{Experimental}

Nano-size particles of mullite are synthesized by combustion (sample I) and sol-gel (sample II) methods. The details of synthesis of both the methods are given elsewhere [10,11]. Pellets of $1 \mathrm{~mm}$ thickness and $6 \mathrm{~mm}$ diameter are prepared using agate and mortar and polyvinyl alcohol as binder and by applying a pressure of 6 tones per ram of $6 \mathrm{~mm}$ diameter using an home made pelletizer. The pellets of sample I and II are bombarded with $100 \mathrm{MeV} \mathrm{Ni}^{8+}$ ions from $16 \mathrm{MV}$ pelletron at Nuclear Science Center, New Delhi. For in situ PL measurements a Kimmon $\mathrm{He}-\mathrm{Cd}$ laser through a sapphire window is used. It gives two beams of 325 and $441.6 \mathrm{~nm}$ wavelengths with powers of 32 and $120 \mathrm{~mW}$, respectively. A mirror to make it incident on a sample kept in vacuum chamber deflects laser beam. A vacuum-sealed optical sapphire window is provided in a chamber for collection of fluorescent light. The entry of the laser beam from the ground level is the same so that the effect of ion irradiation in the sample can be studied by simply switching the beam on and off. The schematic diagram of in situ PL experimental setup is shown in Fig. 1.

\section{Results and discussion}

Photoluminescence of mullite samples I and II irradiated with $100 \mathrm{MeV} \mathrm{Ni}^{8+}$ ions for fluences in the range $1 \times 10^{11}-1 \times 10^{14}$ ions $/ \mathrm{cm}^{2}$ followed by $442 \mathrm{~nm}$ laser beam excitation are recorded and the results obtained are presented in Figs. 2 and 3, respectively. A broad emission band with peak at $\sim 557 \mathrm{~nm}$ besides a sharp emission band with peak at $705 \mathrm{~nm}$ is observed in sample I. However, a single emission band with peak at about $537 \mathrm{~nm}$ is recorded in sample II. The PL intensity in both samples I and II are found to decrease with increase of ion fluence as shown in Fig. 4. This may be attributed to irradiation induced amorphization as a result of cascade quenching $[5,12]$. Amorphization may take place in the system as each incident ion may create one or several displacement cascades, which become amorphous as a result of rapid quenching, and these cascades eventually overlap to form an amorphous solid [5]. The susceptibility of amorphization may be measured in two ways: (i) the ion dose required for 


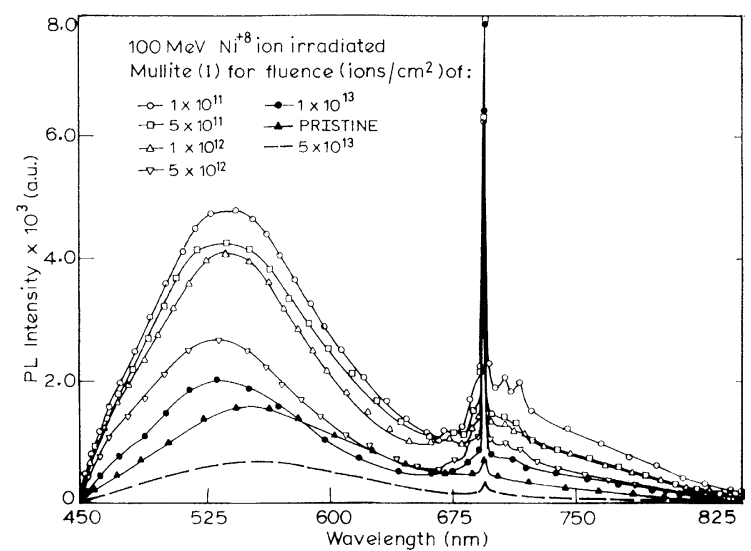

Fig. 2. Photoluminescence spectra of $100 \mathrm{MeV} \mathrm{Ni}^{8+}$ ion irradiated combustion synthesized mullite ( $\lambda_{\text {excitation }} 442 \mathrm{~nm}$ ).

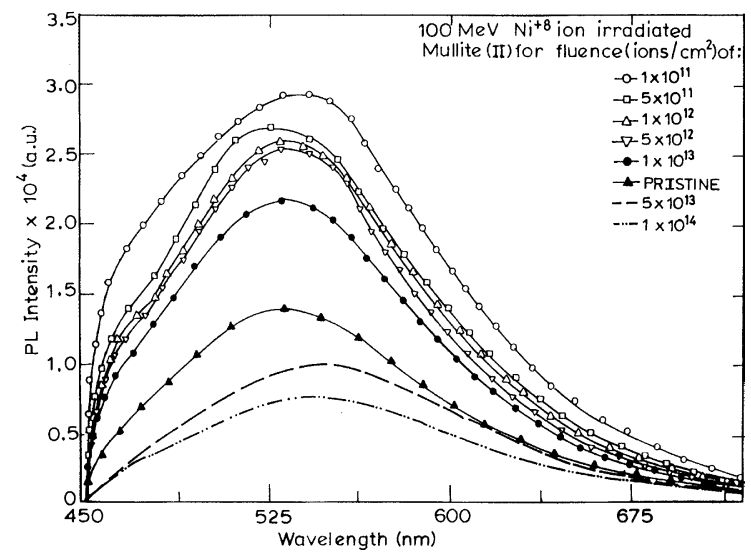

Fig. 3. Photoluminescence spectra of $100 \mathrm{MeV} \mathrm{Ni}^{8+}$ ion irradiated mullite synthesized by sol-gel technique $\left(\lambda_{\text {excitation }} 442\right.$ $\mathrm{nm})$.

amorphization at a fixed irradiation temperature or (ii) the critical temperature. Wang et al. [5] have observed the complete amorphization in $\mathrm{Al}_{2} \mathrm{SiO}_{5}$ by monitoring the selected area diffraction technique (SAD) under $1.5 \mathrm{MeV} \mathrm{Xe}^{+}$ions with the fluence of $1.88 \times 10^{14} \mathrm{ions} / \mathrm{cm}^{2}$, and the critical temperature for amorphization of kyanite was observed to be $1281 \mathrm{~K}$. It is also found that the PL intensity in sample I is more compared to that in sample II. This is attributed to the physical nature of the sample, preparation conditions and/or ingredients used in the preparation of phosphor.

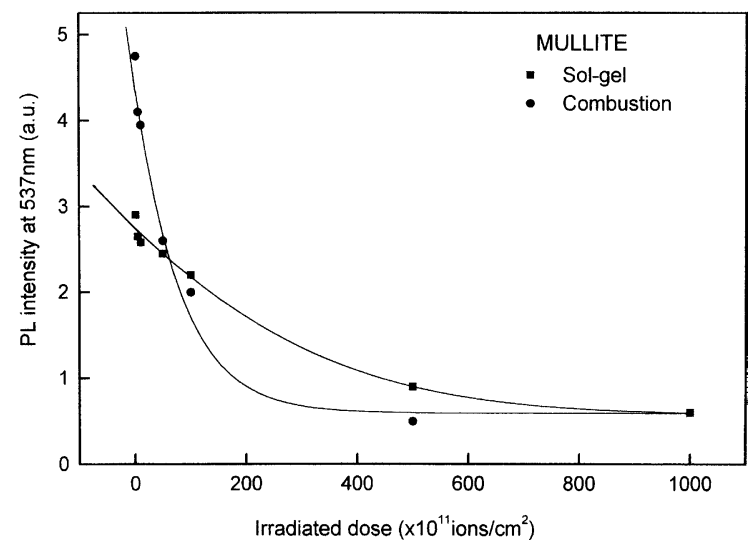

Fig. 4. Variation of PL intensity as a function of ion dose in mullite (I and II).

The infrared absorption of as it is and that of ion irradiated mullite (I and II) with a fluence of $1 \times 10^{13}$ ions $/ \mathrm{cm}^{2}$ have been studied and the results obtained for combustion synthesized mullite are given in the Fig. 5 as illustration. The data obtained from IR results on these samples (I and II) are given in the Table 1 . The spectra reveals the characteristic absorption bands of silicates and water before irradiation of the samples. It is observed that the sharpness of the peaks is high in ion irradiated samples. This could be attributed to close packing of the molecules or to conformational changes in the molecules or both [13]. The

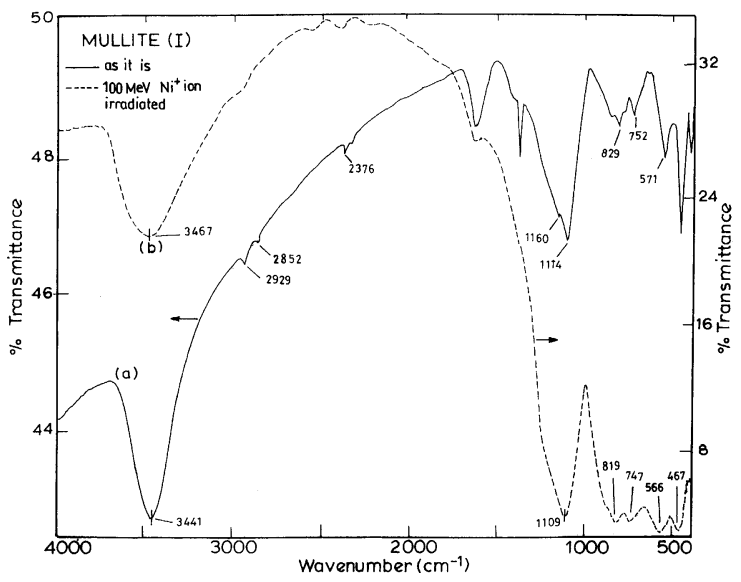

Fig. 5. Infrared spectrum of mullite (I) (a) as it is (b) $100 \mathrm{MeV}$ $\mathrm{Ni}^{8+}$ ion irradiated for $1 \times 10^{13}$ ions $/ \mathrm{cm}^{2}$. 
Table 1

Infrared data of unirradiated and irradiated mullites (I and II)

\begin{tabular}{llll}
\hline Sample & $\begin{array}{l}\text { Absorption } \\
\text { peak }\left(\mathrm{cm}^{-1}\right)\end{array}$ & $\begin{array}{l}\text { Unirradiated } \\
\text { sample }\end{array}$ & $\begin{array}{l}\text { Irradiated } \\
\text { sample }\end{array}$ \\
\hline Mullite (I) & $467-472$ & $\mathrm{Si}-\mathrm{O}\left(\gamma_{4}\right)$ & $\mathrm{Si}-\mathrm{O}\left(\gamma_{4}\right)$ \\
& $566-571$ & $\mathrm{Si}-\mathrm{O}-\mathrm{Al}$ & $\mathrm{Si}-\mathrm{O}-\mathrm{Al}$ \\
& $747-829$ & $\mathrm{Al}-\mathrm{O}$ & $\mathrm{Al}-\mathrm{O}$ \\
& $1109-1114$ & $\mathrm{Si}-\mathrm{O}\left(\gamma_{3}\right)$ & $\mathrm{Si}-\mathrm{O}\left(\gamma_{3}\right)$ \\
& 1160 & $\mathrm{Si}-\mathrm{O}\left(\gamma_{2}\right)$ & - \\
& $2376-2929$ & $\mathrm{Si}-\mathrm{O}\left(2 \gamma_{3}\right)$ & $\mathrm{Si}-\mathrm{O}\left(2 \gamma_{3}\right)$ \\
& $3441-3461$ & $-\mathrm{OH}\left(\gamma_{1}, \gamma_{3}\right)$ & $-\mathrm{OH}\left(\gamma_{1}, \gamma_{3}\right)$ \\
& & & \\
Mullite (II) & $447-467$ & $\mathrm{Si}-\mathrm{O}\left(\gamma_{4}\right)$ & $\mathrm{Si}-\mathrm{O}\left(\gamma_{4}\right)$ \\
& $591-638$ & $\mathrm{Al}-\mathrm{O}$ & - \\
& $1093-1103$ & $\mathrm{Si}-\mathrm{O}\left(\gamma_{3}\right)$ & $\mathrm{Si}-\mathrm{O}\left(\gamma_{3}\right)$ \\
& $2350-2850$ & $\mathrm{Si}-\mathrm{O}\left(2 \gamma_{3}\right)$ & - \\
& $3452-3462$ & $-\mathrm{OH}\left(\gamma_{1}, \gamma_{3}\right)$ & $-\mathrm{OH}\left(\gamma_{1}, \gamma_{3}\right)$ \\
\hline
\end{tabular}

decrease in the PL intensity in both the samples might be due to the destruction of $\mathrm{Si}-\mathrm{O}$ and $\mathrm{Al}-\mathrm{O}$ bonds. And, the destruction of these bonds with irradiation may further enhance the amorphous nature of the sample. The irradiation effects may lead to the restructuring of the surface chemical species because of the energy deposited through electronic loss during the process of swift heavy ion irradiation and, formation of ion induced defects leading to non-radiative recombination centers. These two processes are simultaneous consequences of irradiation and they compete with each other. Consequently, the enhancement or degradation of PL might be due to the balance between these two effects [14].

\section{Conclusion}

The decrease in PL intensity with increase of ion fluence might be due to destruction of Al-O and $\mathrm{Si}-\mathrm{O}$ bonds in the present samples. However, the enhancement in the PL intensity in combustion synthesized mullite (I) compared to that in sol-gel technique (II) is attributed to the process of preparation of the sample, which leads to variation in particle size.

\section{Acknowledgements}

One of the authors (H.N.) is thankful to NSC for the financial assistance.

\section{References}

[1] C. Trautmann, M. Toulemonde, K. Schwartz, J.M. Costantini, A. Muller, Nucl. Instr. and Meth. B 164-165 (2000) 365.

[2] M. Toulemonde, S. Bouffard, F. Studer, Nucl. Instr. and Meth. B 91 (1994) 108.

[3] R. Katz, K.S. Loh, L. Daling, G.R. Huang, Radiat. Eff. Def. Solids 114 (1990) 15.

[4] E. Balanzat, S. Bouffard, A. Cassimi, E. Dooryhee, L. Protin, J.P. Grandin, J.L. Doualan, J. Margerie, Nucl. Instr. and Meth. B 91 (1994) 134.

[5] S.X. Wang, L.M. Wang, R.C. Ewing, Nucl. Instr. and Meth. B 127-128 (1997) 186.

[6] T.M. Bhave, S.V. Bhoraskar, P. Singh, V.N. Bhoraskar, Nucl. Instr. and Meth. B 132 (1997) 409.

[7] P. Hensen, H. Heitmann, P.H. Smit, Phys. Rev. B 29 (1982) 3539.

[8] Y. Zhu, Z.X. Cai, R.C. Budhani, M. Suenaga, D.O. Welch, Phys. Rev. B 48 (1993) 6436.

[9] E.S. Dana, E.M. Ford, Minerology, Asia Publishing House, Bombay, 1962, p. 617.

[10] R.G. Chandran, K.C. Patil, G.T. Chandrappa, Int. J. SelfPropag. High-Temp. Synth. 3 (1994) 13.

[11] P. Brovetto, A. Delunas, V. Maxia, M. Salis, G. Spano, Nuovo Cimento D 13 (1991) 1379.

[12] T. Diaz de la Rubia, G.H. Gilmer, Phy. Rev. Lett. 74 (1995) 2507.

[13] S. Narasimha Reddy, P.S. Rao, R.V.S.S.N. Ravikumar, B.J. Reddy, Indian J. Phys. 75A (2001) 429.

[14] T.M. Bhave, S.S. Hullavarad, S.V. Bhoraskar, S.G. Hegde, D. Kangilal, Nucl. Instr. and Meth. B 156 (1999) 121. 